\title{
Self-ignition temperature of the dust accumulations for sunflower and wood powders
}

\author{
Maria Prodan $^{1 *}$, Andrei Szollosi-Moța ${ }^{1}$, Vasilica Irina Nălboc ${ }^{1}$, Niculina Sonia Șuvar ${ }^{1}$, \\ and Adrian Jurca ${ }^{1}$; \\ ${ }^{1}$ National Institute for Research and Development for Mine Safety and Protection to Explosion \\ INSEMEX Petrosani, 32-34 G-ral. Vasile Milea Street, Petrosani, Romania
}

\begin{abstract}
Spontaneous combustion is a phenomenon that results from the heating of combustible organic powders by slow oxidation and which occurs through the air passage (created by an air depression) through the mass of dust. The oxidation phenomenon of combustible powders represents their reaction with atmospheric oxygen resulting in products of carbon dioxide, carbon oxide, water and other gases whose content depends on the temperature at which the oxidation takes place. The selfignition of combustible dusts depends on their chemical composition, the properties of component substances, on the particle size and geometry of the material mass and, last but not least, on the temperature of the environment. Due to global worries of sustainability in construction engineering the trend is to use ecofriendly organic waste to various purposes as in construction materials. The challenge is that by using this kind of materials one should ensure the safety related to the process of such organic materials which are known to have combustible properties. The purpose of this work is to present the self-ignition behavior of combustible dusts such as sunflower and wood by means of drying tests under constant temperature conditions.
\end{abstract}

\section{Introduction}

According to BS 2955: 1958, [68], materials with a particle size of less than $1000 \mu \mathrm{m}$ are defined as "powders" and particles with a diameter of less than $76 \mu \mathrm{m}$ are defined as "powders". On the other hand, NFPA 68 [1] defines dust as any finely divided particle having a diameter of $420 \mu \mathrm{m}$ or less. More than $70 \%$ of the powders processed in industry are combustible [2]. This makes most industrial applications that process dust susceptible to explosions [3].

"Dust" is the well-known notion for materials obtained by crushing solids beyond a certain degree of fineness. This notion therefore also includes materials commonly known as powder, flour, powder, etc. Dust consists of a lot of solid particles, whose main property, which distinguishes them from other fragmented solids, is their very low rate of fall in gases in general and in air in particular. Dust particles in a volume of air, without touching

\footnotetext{
* Corresponding author: maria.prodan@insemex.ro
} 
each other, form a mixture of powder - air. In this case the air is the dispersing agent, and the powder particles are called the dispersed phase. Such mixtures have in some respects similarities to gaseous mixtures. When powder particles are at rest on a substrate and touch each other, they are referred to as "powder layers" or "powder deposits". In this state the dust can be compared to some extent with a porous body [4].

A hybrid mixture is a combination of flammable gas and combustible powder, where the gas may be present in a concentration lower than its lower explosion limit and also a smaller amount of powder than its minimum explosion concentration. However, combined, this mixture can be explosive [5]. Eckhoff, [6] demonstrated that the addition of flammable gas to a cloud of combustible powder increases the violence of the explosion.

Also, Amyotte, [7], demonstrated experimentally that the maximum explosion pressure (Pmax) and the maximum rate of increase of pressure at constant volume rendered by severity factor (Kst) is higher for hybrid mixtures: ethene / polyethylene, hexane / polyethylene and propane / polyethylene. The hybrid methane / coal powder mixture is the most dangerous and volatile hybrid mixture in underground coal mines. In addition, there are several examples of hybrid mixtures formed in industrial processes, such as natural gas and fly ash in coal-fired power plants and various hydrocarbons and resins from the production of plastic powders [7].

In order to occur, explosions of powder and hybrid mixtures require five basic components [8]:
1. Fuel;
2. Oxidant (air);
3. Source of initiation;
4. Mixing fuel in the air;
5. A certain degree of closure.

Most explosion events take place inside process equipment (eg mills, silos, cyclones, pipelines) [1].

Additionally, one or more explosions may occur after the pressure wave of the first explosion. These strong pressure waves can disperse the dust deposited in the area, forming a new cloud of dust that can be initiated by the energy released by the first explosion. Secondary explosions may be even stronger than the first explosion due to the greater amount of powder or hybrid mixture.

The most important and often reported in the literature explosive parameters for combustible dusts are, according to the series of standards SR EN 14034-1,2,3: Determination of explosion characteristics of powder clouds, [8]:

- Maximum explosion pressure Pex - the highest overpressure that occurs during an explosion of a powder mixture in a closed vessel;

- Maximum pressure rise rate $(\mathrm{dP} / \mathrm{dt}) \max$ - the maximum value of the pressure increase per unit time during explosions [9], for all explosive atmospheres in the explosive range of combustible substances in a closed vessel under the specified test conditions and atmospheric conditions standard;

- Severity factor - Kmax, Kst volume independent characteristic that is calculated using the cubic equation:

$$
\left(\frac{d P}{d t}\right)_{\max } \cdot V^{\frac{1}{3}}=\text { const. }=K_{s t}=K_{\max }
$$

- Minimum explosion concentration or lower explosion limit (CmEx, LIE or LEL) the minimum concentration of combustible dust mixed with air at which the explosion no longer occurs;

- Minimum ignition energy MIE - the lowest electrical energy stored in a capacitor which at discharge is sufficient to produce an ignition of the most flammable mixture of a given powder under specific test conditions; 
- Minimum ignition temperature of a cloud of dust MIT - the lowest temperature of a hot surface at which self-ignition of a cloud of dust occurs under specified test conditions;

- Minimum ignition temperature of the LIT powder layer - the lowest temperature of a hot surface at which a powder layer with a specified thickness is ignited deposited on this hot surface;

The values of these parameters can be found in the literature or in online databases, but these values should be seen as indications and not as a basis for the design of safety measures in industry, which should be based on specific data for each powder in part.

It is important to know that these parameters are not intrinsic properties of materials. They are highly dependent on both the properties of the material (moisture, particle size, shape, porosity) and the experimental conditions (vessel volume, degree of turbulence of the powder cloud, source of applied initiation and its energy) [10].

The max parameter $(\mathrm{dP} / \mathrm{dt})$ is dependent on the volume of the blast chamber and cannot be used for vessels with different volumes. To scale to higher volumes, the maximum pressure increase rates are normalized by multiplying the volume of the explosion chamber by the cubic root. This procedure also has no well-founded theoretical justification and is disputed by some researchers [11].

The maximum rate of increase of pressure, obtained at a powder-air explosion, is not only a measure of appreciation of the explosiveness of the powder but is a key property that underlies some explosion detection and protection systems.

The pressure generated in the closed blast vessel has little relevance for explosions in open spaces (chambers). Windows, doors, walls yield to pressures that are $1 \%$ of the pressure increases obtained in closed explosion cells. The maximum explosion pressure in this case is determined by the size and resistance pressures of these exhaust zones. In the case of buildings, the windows act as an outlet for the explosion. In industrial buildings there are pressure release systems to avoid damage [12].

The self-ignition behavior of dusts and granular materials and their mixtures depends on their chemical composition as well as on related substance and bulk properties. It also depends on the size and geometry of the body of material, and, last but not least on the ambient temperature.

The reason for self-heating (with possible self-ignition) is that the surface molecules of combustible dust or granular materials undergo exothermic reactions with air or other oxidising atmospheres transported into the void volume between the particles even at normal ambient temperatures. Any heat then released will cause the temperature of the reactive system to rise, thus accelerating the reaction of additional molecules with oxygen, etc. A heat balance involving the heat produced inside the bulk (quantity and surface of reactive surface molecules, specific heat producing rate) and the heat loss to the surroundings (heat conductivity and dimension of the bulk, heat transfer coefficient on the outside surface of the bulk and the size of the latter) is decisive as to whether a steady-state temperature is reached at a slightly higher temperature level (the heat loss terms are larger than the heat production term), or whether temperatures in the bulk will continue to rise up to self-ignition of the material, if heat transport away from the system is insufficient (in this case the heat production term is larger than all heat losses) [11].

The experimental basis in this document for describing the self-ignition behavior of a given dust or granular material is the determination of the self-ignition temperatures (TSI) of differently sized bulk volumes by isoperibolic hot storage experiments (storage at constant oven temperatures) in commercially available ovens. The results thus measured reflect the dependence of self-ignition temperatures upon volume of the accumulation [13].

In this paper was evaluated the self-ignition behavior for several combustible dusts, sunflower husks, hardwood and softwood. 


\section{Materials and methods}

\section{Materials}

Were performed tests to determine the self-ignition temperature for the sunflower husks, softwood and hardwood dust, shown in Figure 1, 2, 3. The samples used were representative, obtained under normal operating conditions of the process.

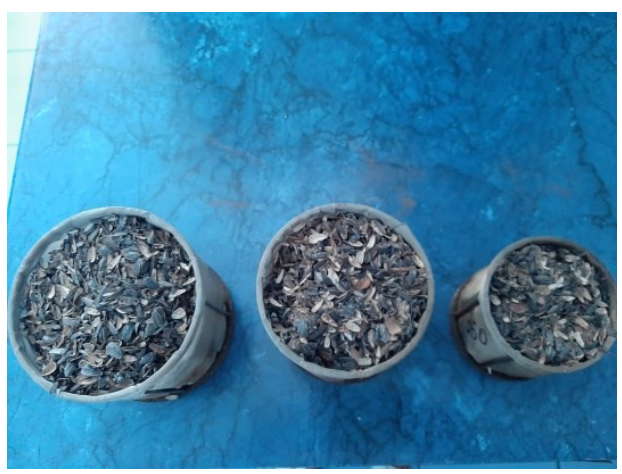

Fig. 1. Test sample sunflower husks

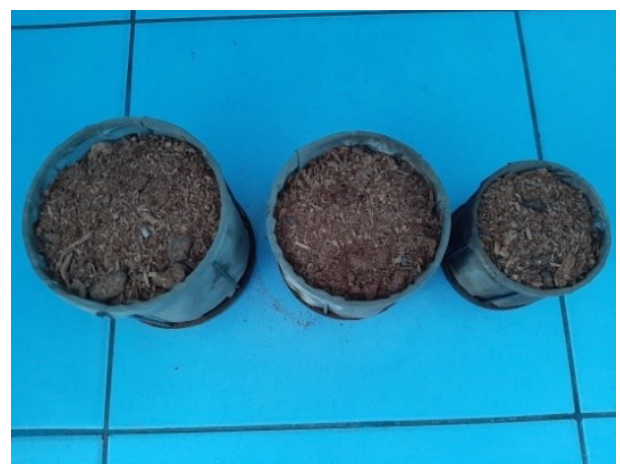

Fig. 2. Test sample hardwood dust

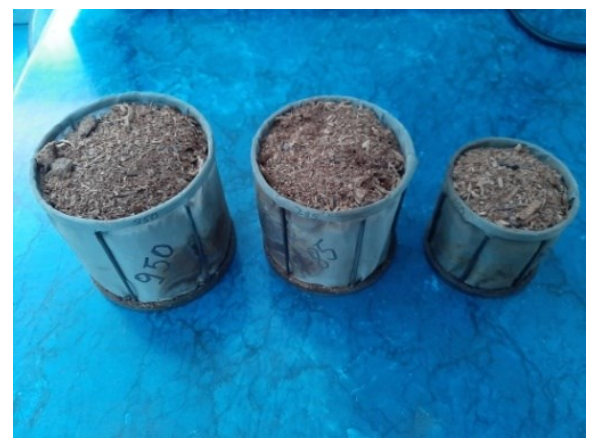

Fig. 3. Test sample softwood dust

\section{Experimental method}

The experimental setup used to perform the tests is performed in accordance with the requirements of the standard SR EN 15188: 2008, and is shown in Fig. 4.

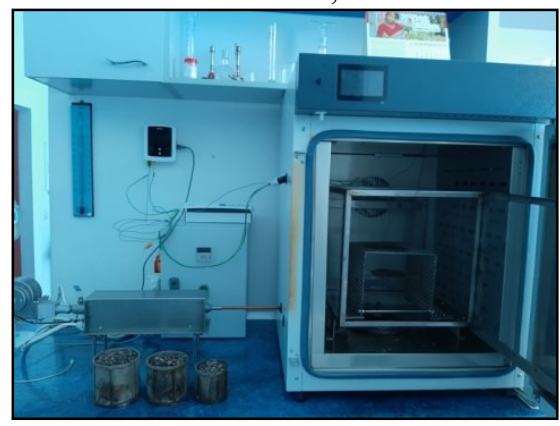

Fig. 4. Experimental assembly for hot steaming tests 
The method used for the determinations specifies analysis and evaluation procedures for determining self-ignition temperatures (TSI) of combustible dusts or granular materials as a function of volume by hot storage experiments in ovens of constant temperature. The specified test method is applicable to any solid material for which the thermal explosion theory according to A.2 holds (i.e. not limited to only oxidatively unstable materials). The specified test is applicable to any dust or granular material that reacts primarily with oxygen from the air. For safety reasons, this test is not used with materials mixed with solid/liquid oxidant (e.g. gunpowder, thermites, wood impregnated with liquid oxygen) or materials that could undergo violent non-oxidative reactions (e.g. peroxides, explosives). On a case by case basis, some types of materials undergoing non-oxidative reactions (e.g. non-violent exothermic decomposition reactions) may be however tested provided that additional safety precautions are taken. Where any doubt exists about the existence of hazard due to the properties of the test material (e.g. toxic or explosive), expert advice is sought.

Thermocouples with a protective coating with an outer diameter of approximately $1 \mathrm{~mm}$ and a data acquisition system corresponding to the recording of signals from thermocouples were used to measure and record the temperature of the sample and the oven.

To determine whether or not self-ignition occurs, there are two methods:

a. When the temperature in the center of the sample rises by at least $60 \mathrm{~K}$ above the oven temperature;

b. When the temperature in the center of the sample shows an inflection point, relative to time, if it appears above the oven temperature, figure 5 [14].

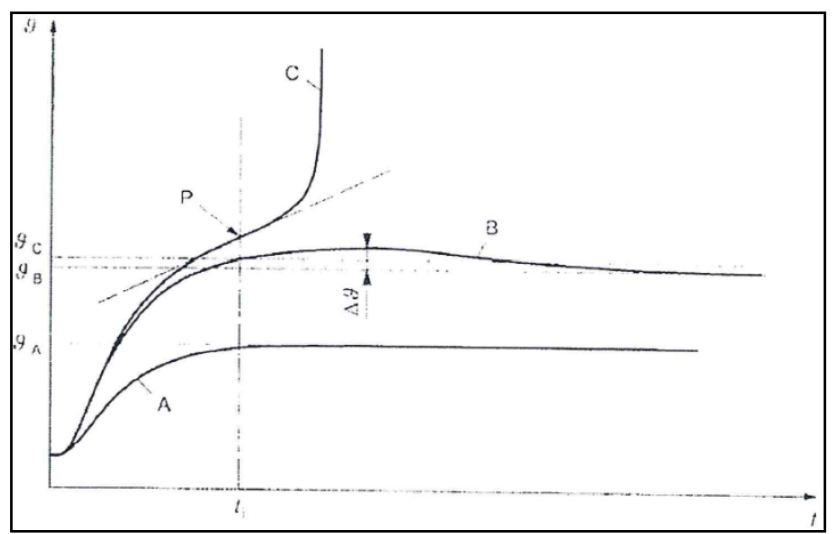

Legend: $\mathrm{g}$ temperature, $\mathrm{t}$ duration of the test, $\mathrm{P}$ inflection point

Fig. 5. Ideal time-varying temperature variation curves for dust samples of the same volume at different evaporation temperatures

If working at significantly lower temperatures, the sample temperature will approach asymptotically the oven temperature (curve A). At higher oven temperatures, significant reactions with oxygen take place in the dust mass, the sample temperature will be temporarily higher than the oven temperature and the self-heating process will start, without igniting the sample. Thereafter, the sample temperature decreases to the oven temperature (curve B). The heat production in the sample has reached a point where it continuously exceeds the heat loss (through heat conduction, convection and radiation). After an induction time, the sample temperature rises rapidly until self-ignition occurs (curve $\mathrm{C}$ ). The self-ignition temperature is between the furnace temperatures of curves B and C. For each test, the time interval between placing the sample in the oven and reaching the steaming temperature and the total steaming time was recorded. In addition, the time 
interval between reaching the steaming temperature and ignition was recorded, reaching the maximum temperature [14].

\section{Results and discussions}

Following the analysis, the results presented in the table 1 below were obtained for the sunflower husks, as well as the graphs in figs. 6,7.

Table 1. Sunflower husks

\begin{tabular}{|c|c|c|c|}
\hline $\begin{array}{c}\text { Characterization of the } \\
\text { sample }\end{array}$ & $\begin{array}{c}\text { Dust volumes tested } \\
\mathbf{( c m 3 )}\end{array}$ & $\begin{array}{c}\text { Auto-ignition } \\
\text { temperature }\left({ }^{\circ} \mathbf{C}\right)\end{array}$ & $\begin{array}{c}\text { Induction } \\
\text { time } \\
\text { (hours) }\end{array}$ \\
\hline \multirow{2}{*}{ Sunflower husks } & 185 & 190 & 0.75 \\
\cline { 2 - 4 } & 380 & 170 & 1.9 \\
\cline { 2 - 4 } & 995 & 160 & 2.5 \\
\hline
\end{tabular}

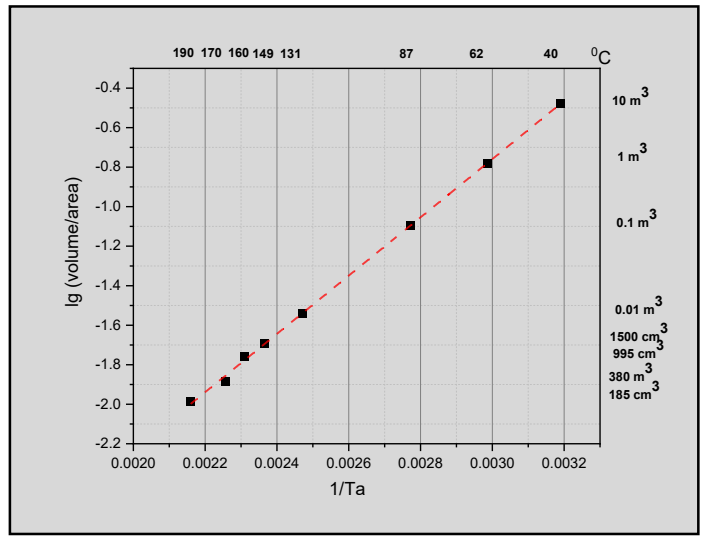

Fig. 6. Graphical representation of ignition temperatures after Arrhenius for the sunflower husks samples

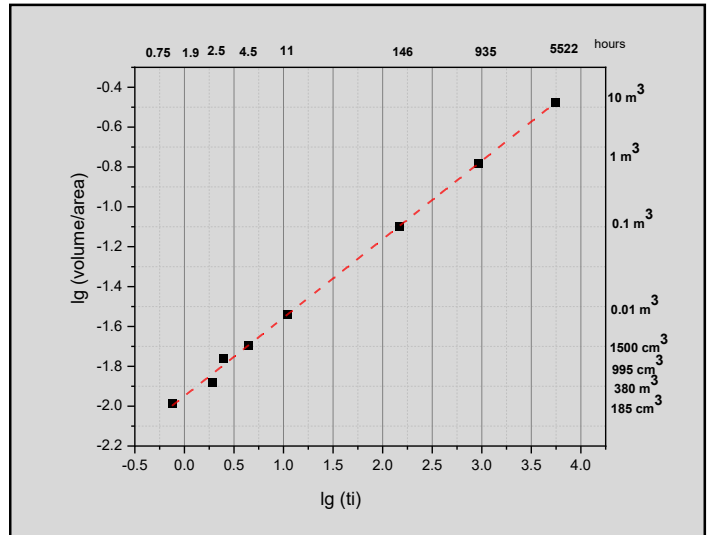

Fig. 7. Dependence of the induction time of the combustion (ti) on the volume / surface ratio

Following the analysis, the results presented in the table 2 below were obtained for the softwood dust, as well as the graphs in figs. 8, 9 . 
Table 2. Softwood dust

\begin{tabular}{|c|c|c|c|}
\hline $\begin{array}{c}\text { Characterization of the } \\
\text { sample }\end{array}$ & $\begin{array}{c}\text { Dust volumes tested } \\
(\mathbf{c m} 3)\end{array}$ & $\begin{array}{c}\text { Auto-ignition } \\
\text { temperature }\left({ }^{\circ} \mathbf{C}\right)\end{array}$ & $\begin{array}{c}\text { Induction time } \\
\text { (hours) }\end{array}$ \\
\hline \multirow{3}{*}{ Softwood dust } & 185 & 180 & 2 \\
\cline { 2 - 4 } & 380 & 170 & 2.35 \\
\cline { 2 - 4 } & 995 & 155 & 3.15 \\
\hline
\end{tabular}

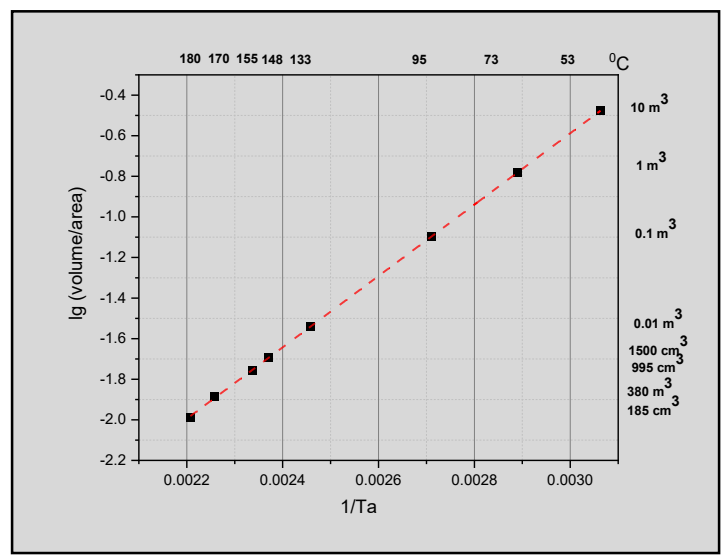

Fig. 8. Graphical representation of ignition temperatures after Arrhenius for the softwood samples

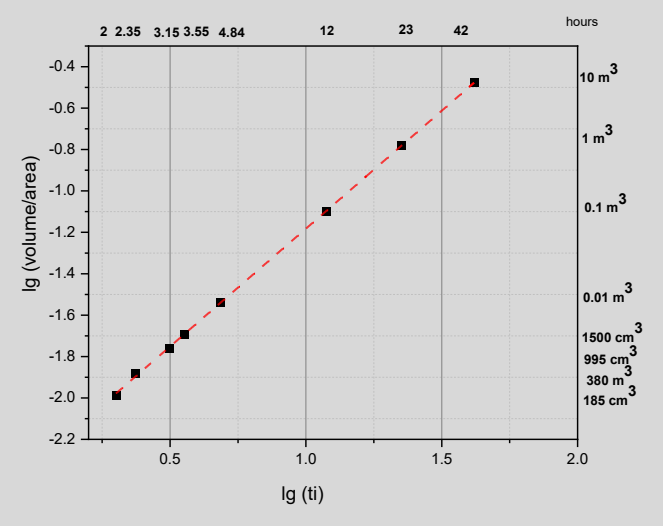

Fig. 9. Dependence of the induction time of the combustion (ti) on the volume / surface ratio

Following the analysis, the results presented in the table 3 below were obtained for the hardwood dust, as well as the graphs in figs. 10, 11 .

Table 3. Hardwood dust

\begin{tabular}{|c|c|c|c|}
\hline Characterization of the sample & $\begin{array}{c}\text { Dust volumes tested } \\
\mathbf{( c m 3 )}\end{array}$ & $\begin{array}{c}\text { Auto-ignition } \\
\left.\text { temperature } \mathbf{(}^{\circ} \mathbf{C}\right)\end{array}$ & $\begin{array}{c}\text { Induction time } \\
\text { (hours) }\end{array}$ \\
\hline \multirow{2}{*}{ Hardwood dust } & 185 & 180 & 2.05 \\
\cline { 2 - 4 } & 380 & 170 & 3 \\
\cline { 2 - 4 } & 995 & 160 & 3.2 \\
\hline
\end{tabular}




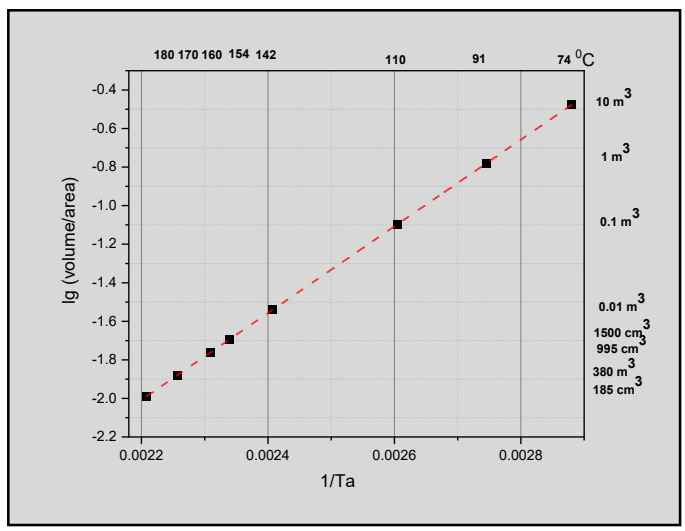

Fig. 10. Graphical representation of ignition temperatures after Arrhenius for the hardwood samples

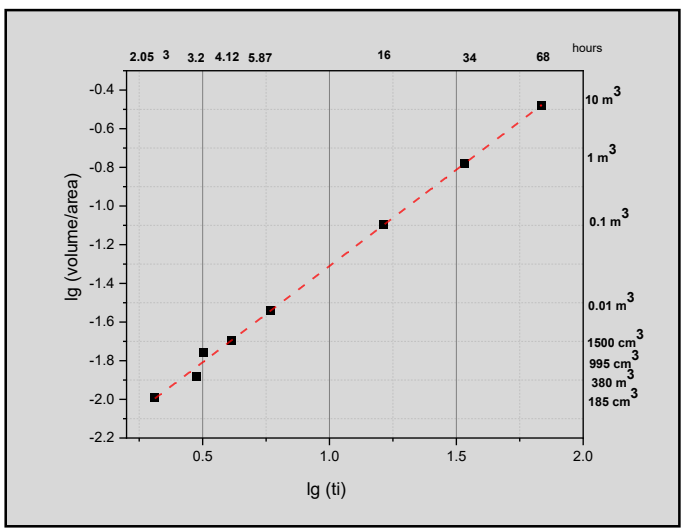

Fig. 11. Dependence of the induction time of the combustion (ti) on the volume / surface ratio

In the figures 6,8 and 10 , there is the Tsi variation for several dust volumes in form of chart $\lg (\mathrm{V} / \mathrm{A})$ function of $1 / \mathrm{T}$. The line that crosses the Tsi values, separates the equilibrium regions from the unstable regions for the dust volumes. The self-ignition occurs in the region above the curve.

In the figure 7,9 and 11 the induction times, required for the critical ignition for different dust volumes, were plotted as $\lg (\mathrm{ti})$ function of $\lg (\mathrm{V} / \mathrm{A})$. From this figure the induction time for the self-ignition of the dust samples deposited at temperatures over the ignition temperature can be deduced.

Combining the two graphs one can know the maximum time that a certain volume of dust can be deposited so that it doesn't reach the self - ignition temperature. Based on those values the safety manager can take the proper measures in order to avoid unwanted events.

In general, self-ignition or spontaneous combustion is limited to the contact of solids with high specific surfaces. Oxygen can react on surfaces in the entire amount, as long as the air exchange is large enough. The oxidation process can begin at room temperature depending on the substance.

As an example, a cylindrical volume of $1 \mathrm{~m}^{3}$ of sunflower husks has a self-ignition temperature higher than $62{ }^{\circ} \mathrm{C}$. If this volume of sunflower husks is stored at this constant temperature, 38 days will elapse before an ignition could occur. 
A cylindrical volume of $10 \mathrm{~m}^{3}$ of hardwood dust has a self-ignition temperature higher than $74{ }^{\circ} \mathrm{C}$. If this volume of dust is stored at this constant temperature, 68 hours will elapse before an ignition could occur.

Self-ignition of bulk dust is caused by the rate of heat production, oxidation and / or decomposition reactions of the dust, which is higher than the rate of heat loss.

In general, self-ignition or spontaneous combustion is limited to the contact of solids with high specific surfaces. Oxygen can react on surfaces in the entire amount, as long as the air exchange is large enough. The oxidation process can begin at room temperature depending on the substance [14].

\section{Conclusions}

Although all precautions are taken in the dust industry, there are often situations that lead to loss of life and significant material damage. Thus, in the drying processes, self-ignition, respectively fires of dust accumulations is considered as the main cause for such incidents.

Self-ignition is a common source of ignition in the storage of bulk materials, such as dust and dust. The assessment of this ignition hazard takes into account the manufacturing or storage conditions and requires the experimental determination of critical self-ignition temperatures as a function of volume.

The experimental results showed that the dust tested are combustible and based on the graphs obtained the safety measures can be taken such that unwanted fires and explosions can be avoided.

This paper was developed within the Nucleu-Programme, carried out with the support of Romanian Ministry Of Research And Innovation, project no. PN 19210103.

\section{References}

1. BS2955, Glossary of Terms Relating to Powders, No. 505, British standard institute, London (1958)

2. NFPA, Guide for Venting of Deflagrations, National Fire Protection Association, National Fire Protection Association (2002)

3. Vijayaraghavan, G, Impact assessment, modelling, and control of dust explosions in chemical process industries, Coimbatore Institute of Technology (2004)

4. T. Abbasi, S. Abbasi, Dust explosions - Cases, causes, consequences, and control, Journal of Hazardous Materials, 140, (2007)

5. I. Krausz, Teza de doctorat, Universitatea din Petrosani, Facultatea de Mine, Petrosani (2008)

6. P. Amyotte, R. Eckhoff, Dust explosion causation, prevention and mitigation: An overview Journal of Chemical Health and Safety, 17, 1, 15-28 (2010)

7. R. Eckhoff, Dust explosions in the process industries, 3rd ed., Burlington: Gulf Professional Publishing (2003)

8. P. Amyotte, M. Abuswer, A. Di Benedetto și P. Russo, Determination of hybrid mixture explosion severity, Brugge, Belgium (2010)

9. P. Amyotte, F. Kahn și A. Dastidar, Reduce dust explosions the inherently safer way, Chemical Engineering Progress, 99, 10, 36-43 (2003)

10. SR EN 14034-1:3, Determination of dust cloud explosion characteristics. Determination of explosion pressure. Determination of the maximum explosion pressure increase value and determination of the lower limit of dust clouds, EN Standard (2011)

11. M. Hertzberg, K.L. Cashdollar, Introduction to dust explosions, in: Proceedings of the Industrial Dust Explosions STP 958, American Society for Testing and Materials, West Conshohocken, 532 (1987)

12. W. Bartknecht, Dust Explosions: Course, Prevention, Protection, Berlin: Springer (1989) 
13. W. Wiemann, Influence of temperature and pressure on the explosion characteristics of dust-air and dust air inert gas mixtures, West Conshohocken (1987)

14. SR EN 15188:2008 Determination of the spontaneous ignition behaviour of dust accumulations (2008) 